\title{
UV-curable nanocasting technique to prepare bioinspired superhydrophobic organic-inorganic composite anticorrosion coatings
}

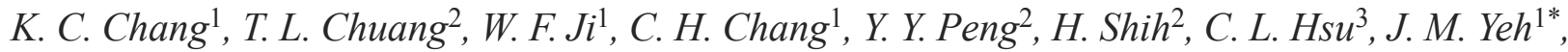 \\ W. C. Tang ${ }^{4}$, Y. C. Su ${ }^{4}$ \\ ${ }^{1}$ Department of Chemistry, Center for Nanotechnology and Biomedical Technology at Chung-Yuan Christian University \\ (CYCU), 32023 Chung Li, Taiwan, Republic of China \\ ${ }^{2}$ Master Program in Nanotechnology and Center for Nanotechnology at CYCU, 32023 Chung Li, Taiwan, Republic of China \\ ${ }^{3}$ Department of Physics, Center for Nanotechnology at Chung-Yuan Christian University (CYCU), 32023 Chung Li, \\ Taiwan, Republic of China \\ ${ }^{4}$ Division of Applied Chemistry, Material and Chemical Research Laboratories, Industrial Technology Research Institute, \\ 30011 Hsinchu, Taiwan, Republic of China
}

Received 4 August 2014; accepted in revised form 4 October 2014

\begin{abstract}
A UV-curing technique was used to develop advanced anticorrosive coatings made of a poly(methyl methacrylate) (PMMA)/silica composite (PSC) with bioinspired Xanthosoma sagittifolium leaf-like superhydrophobic surfaces. First of all, a transparent soft template with negative patterns of xanthosoma sagittifolium leaf can be fabricated by thermally curing the polydimethylsiloxane (PDMS) pre-polymer in molds at $60^{\circ} \mathrm{C}$ for $4 \mathrm{~h}$, followed by detaching PDMS template from the surface of natural leaf. PSC coatings with biomimetic structures can be prepared by performing the UV-radiation process upon casting UV-curable precursor with photo-initiator onto cold-rolled steel (CRS) electrode under PDMS template. Subsequently, UV-radiation process was carried out by using light source with light intensity of $100 \mathrm{~mW} / \mathrm{cm}^{2}$ with exposing wavelength of $365 \mathrm{~nm}$. Surface morphologies of the as-synthesized hydrophobic PMMA (HP) and superhydrophobic PSC (SPSC) coatings showed a large number of micro-scaled mastoids, each decorated with many nano-scaled wrinkles that were systematically investigated by using scanning electron microscopy (SEM). The contact angles of water droplets on the sample surfaces can be increased from $\sim 81$ and $103^{\circ}$ on PMMA and PSC surfaces to $\sim 148$ and $163^{\circ}$ on HP and SPSC surfaces, respectively. The SPSC coating was found to provide an advanced corrosion protection effect on CRS electrodes compared to that of neat PMMA, PSC, and HP coatings based on a series of electrochemical corrosion measurements in $3.5 \mathrm{wt} \% \mathrm{NaCl}$ electrolyte. Enhanced corrosion protection of SPSC coatings on CRS electrodes can be illustrated by that the silica nanoparticles on the small papillary hills of the bioinspired structure of the surface further increased the surface roughness, making the surface exhibit superior superhydrophobic, and thus leading to much better anticorrosion performance.
\end{abstract}

Keywords: coatings, polymer composite, bioinspired, superhydrophobic, anticorrosion

\section{Introduction}

Corrosion is the deterioration of materials by chemical interaction with their environment. The consequences of corrosion are many and varied; corrosion's effects on the safe, reliable, and efficient operation of equipment or structures are often more serious than the simple loss of a metal mass. Several corrosion-control methods are available, such as inhibitors, cathodic protection [1], anodic protection [2], coating [3], and alloying. Among the above methods, polymeric (or organic) coatings have been employed to protect metals against corrosion for a

\footnotetext{
${ }^{*}$ Corresponding author, e-mail: juiming@cycu.edu.tw

(C) BME-PT
} 
long time. The primary effect of a polymeric coating is to function as a physical barrier against corrosive species such as $\mathrm{O}^{2}$ and $\mathrm{H}^{+}$.

Superhydrophobic (or ultrahydrophobic) surfaces are those on which the water contact angle (WCA) is $150^{\circ}$ and higher. A lotus leaf is a classic example of a natural superhydrophobic surface with a WCA of larger than $150^{\circ}$ [4]. The superhydrophobic effect is due to both of low surface energy materials and hierarchical (nano-/macro-) structures. The surface is also characterized by a very low water roll-off angle (i.e., very low WCA hysteresis [5]). Previous research has shown that water droplets on these textured surfaces readily sit on the apexes of the nanostructures because air bubbles fill the valleys of the structures under the droplets. Water drops on such surfaces cannot penetrate the micro- or nanostructures and wet the surface, resulting in extremely high contact angles; thus, these naturally occurring leaves exhibit considerable superhydrophobicity. Numerous methods, including photolithography [6], plasma treatment [7], templates [8], chemical deposition [9], solgel processes [10], chemical vapor deposition (CVD) [11], casting, and chemical etching [12], have been utilized to fabricate superhydrophobic surfaces.

Several studies have been reported on using polymers and polymer nanocomposites for various applications such as fabricating hydrophobic/superhydrophobic surfaces [13-21]. Therefore, development of hydrophobic/superhydrophobic polymers and polymer nanocomposites has become an interesting subject in materials science. Very few studies have reported on the use of polymer and polymer nanocomposite coatings to study the anticorrosive properties that hydrophobic/superhydrophobic surfaces provide [22-26]. However, organic polymerinorganic silica composite anticorrosion coatings with bioinspired superhydrophobic surfaces have never been studied. Therefore, we demonstrated a feasible strategy to develop advanced PMMA/silica composite (PSC) anticorrosion coatings by a nanocasting method along with a UV-curing technique designed to directly duplicate fresh plant leaf surfaces (such as Xanthosoma sagittifolium leaves). The imprint of the approximate superhydrophobic Xanthosoma sagittifolium leaf was transferred onto the composite surface so that the resulting composite exhibited the approximate superhydrophobicity required to prevent corrosion.
Traditionally, some resins utilized for their anticorrosion properties require the use of organic solvents, which significantly increase human health risks. As new regulations regarding the emission of volatile organic compounds (VOCs) are put into effect, increased demands for environmentally friendly (green) coating systems will require the progressive substitution of greener compounds in place of hazardous coatings. Among the alternatives are waterborne and solvent-free coatings. Thus, we developed an eco-friendly process to prepare composite anticorrosion coatings without using solvents. The composite anticorrosion coatings developed in this study provided multiple effects to protect metals from corrosion. One is the bioinspired structure with superhydrophobicity approximately equivalent to that of Xanthosoma sagittifolium leaf that can repel moisture and further reduce the water/corrosive media adsorption on the PMMA surfaces, preventing the underlying metals from corrosion. The other is the silica nanoparticle on the small papillary hills of the bioinspired structure, which enhances the surface hydrophobicity to a superhydrophobic degree, leading to a better anticorrosion effect. The detailed anticorrosion performance of the developed SPSC coatings was evaluated by a series of electrochemical corrosion measurements. Corrosion protection studies were performed on a sample-coated cold-rolled steel (CRS) immersed in a corrosive medium (3.5 $\mathrm{wt} \%$ sodium chloride aqueous solution).

\section{Experimental section}

\subsection{Chemicals and instruments}

Methyl methacrylate (MMA; Aldrich, 99.0\%, USA) was doubly distilled prior to use. Photo-initiator alpha-Benzyl-alpha-(dimethylamino)-4-morpholinobutyro-phenon (Aldrich, 97.0\%, USA), tetraethyl orthosilicate (TEOS; Fluka, 98.0\%, Germany), 3-(trimethoxysilyl)propyl methacrylate (MSMA; Acros, 98.0\%, Belgium), ethanol (EtOH; Riedel-de Haën, 99.8\%, Germany), and ammonium hydroxide solution $\left(\mathrm{NH}_{3}\right.$; Aldrich, $25.0 \%$, USA) were used as received without further purification. The liquid components (Sylgard 184, Dow corning, USA) of polydimethylsiloxane (PDMS) were supplied by the Dow Corning Corporation. All the reagents were of reagent grade unless otherwise stated.

Fourier transform infrared (FTIR) spectra were recorded using an FTIR spectrometer (JASCO FT/ 
IR-4100, Japan) at room temperature. Surface morphologies of the superhydrophobic samples were observed by using SEM (JOEL JSM-7600F, Japan) and AFM (PSIA XE-100 STM SESTAM, Korea). Contact angles were measured using a First Ten Angstroms FTA 125 (USA) goniometer at ambient temperatures. Water droplets (about $4 \mu \mathrm{L}$ ) were carefully dropped onto the surfaces of the samples, and the contact angles were determined from the average of five measurements at various positions on the samples' surfaces. The corrosion potential and corrosion current of sample-coated CRS electrodes were electrochemically measured using a VoltaLab 50 potentiostat/galvanostat. Electrochemical impedance spectroscopy (EIS) measurements were recorded on an AutoLab (PGSTAT302N, Netherlands) potentiostat/galvanostat electrochemical analyzer.

\subsection{Synthesis of vinyl-modified silica (VMS) particles}

VMS particles were prepared by conventional basecatalyzed sol-gel reactions of TEOS in the presence of MSMA molecules (Figure 1a). The procedure was similar to previously described methods [27]. A typical procedure to prepare the VMS particles was given as follows: $0.52 \mathrm{~g}(0.0025$ mole $)$ of TEOS and $2.48 \mathrm{~g}$ ( 0.01 mole) of MSMA were mixed in a $250 \mathrm{~mL}$ beaker under ultrasonic. A separate solution of $50 \mathrm{~mL} \mathrm{H}_{2} \mathrm{O}$ that add a little $15 \mathrm{NNH}_{3}$ to control the $\mathrm{pH}=9$ under magnetically stirring at room temperature. Then, the MSMA and TEOS solution was slowly added into the $\mathrm{H}_{2} \mathrm{O}$ solution with stirring for $12 \mathrm{~h}$ at $60^{\circ} \mathrm{C}$. After the sol-gel reactions, the as-prepared VMS particles were thus obtained. The raw silica (RS) was also prepared through the conventional sol-gel reactions of TEOS molecules simultaneously as control experiments without the addition of MSMA monomers.

\subsection{Preparation of PDMS template}

The PDMS prepolymer was obtained by mixing the elastomer base and a curing agent in a proper ratio $(10: 1, w / w)$. The PDMS pre-polymer was poured into $3 \times 6 \mathrm{~cm}^{2}$ molds fixed to a piece of fresh, natural Xanthosoma sagittifolium leaf (the veins of the leaf were removed in an area of about $3 \times 6 \mathrm{~cm}^{2}$ ) and then cured in a $60^{\circ} \mathrm{C}$ oven for $4 \mathrm{~h}$. After curing, the PDMS blocks were separated from the molds and used as templates for imprinting. The thick of PDMS template was $3.0 \mathrm{~mm}$.

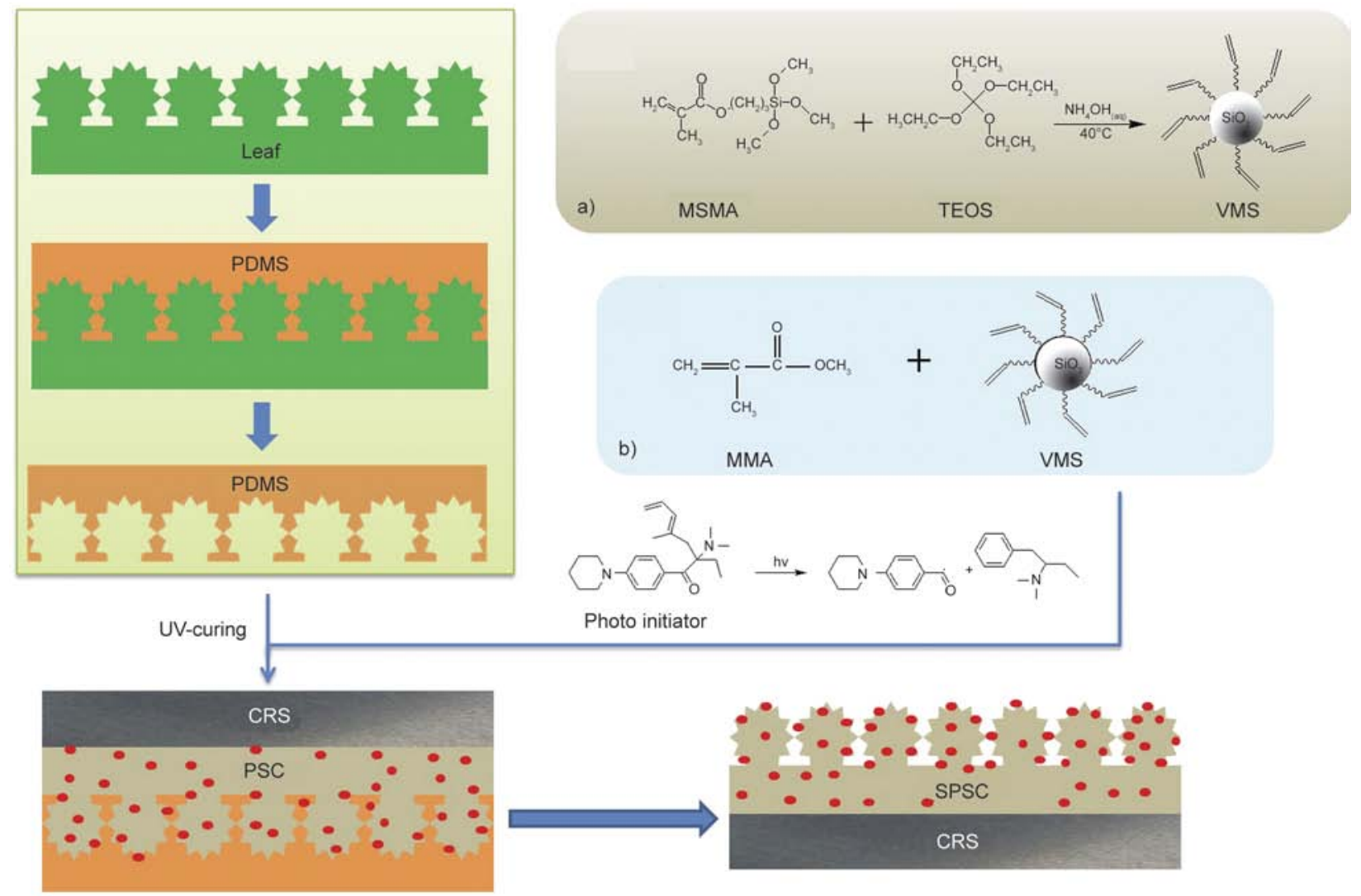

Figure 1. Preparation process of (a) VMS particles and (b) superhydrophobic surfaces of an organic-inorganic composite by using a nanocasting method combined with a UV-curing technique 


\subsection{UV-curable SPSC coatings}

Figure $1 b$ shows a schematic diagram for the fabrication of SPSC coating materials. First, a PDMS prepolymer was cast against a fresh Xanthosoma sagittifolium leaf surface and then cured under appropriate conditions. The prepared PDMS template has negative Xanthosoma sagittifolium leaf surface structures, and was obtained after peeling the leaf off. Second, the substrate was covered with the UV-curable precursor solution, and the template was pressed against the CRS. It was then exposed to UV-light (fusion UV-curing, light intensity $=2000 \mathrm{~mJ} / \mathrm{cm}^{2}$ ) for $300 \mathrm{~s}$. After the UV-curing process and peeling off the PDMS template, a Xanthosoma sagittifolium leaf-like surface was formed on the CRS.

\subsection{Electrochemical measurements of coatings}

Electrochemical corrosion measurements were performed using a VoltaLab 50 device. All the electrochemical corrosion measurements were performed in a double-wall jacketed cell, covered with a glass plate, in which water was maintained at a constant operational temperature of $25 \pm 0.5^{\circ} \mathrm{C}$. The open-circuit potential (OCP) in the equilibrium state of the system was recorded as the corrosion potential ( $E_{\text {corr }}$ in $\mathrm{mV}$ versus a saturated calomel electrode (SCE)). Tafel plots were obtained by scanning the potential from -500 to $500 \mathrm{mV}$ above $E_{\text {corr }}$ at a scan rate of $10 \mathrm{mV} / \mathrm{min}$. The corrosion current $\left(I_{\text {corr }}\right)$ was determined by superimposing a straight line along the linear portion of the cathodic or anodic curve and extrapolating it through $E_{\text {corr }}$. The corrosion rate $\left(R_{\text {corr }}\right.$, in milli-inches per year, MPY) was calculated using Equation (1) [28]:

$R_{\mathrm{corr}}[\mathrm{MPY}]=\frac{0.13 I_{\mathrm{corr}}(E . W .)}{A \cdot d}$

where $E . W$. is the equivalent weight [g/eq.], $A$ is the area $\left[\mathrm{cm}^{2}\right]$, and $d$ is the density $\left[\mathrm{g} / \mathrm{cm}^{3}\right]$.

An AutoLab (PGSTAT302N) potentiostat/galvanostat was employed to perform the a.c. impedance spectroscopy measurements. The impedance measurements were carried out in the frequency range $100 \mathrm{kHz}-100 \mathrm{MHz}$ with pure iron (area, $1 \times 1 \mathrm{~cm}^{2}$ ) as the working electrode embedded in epoxy, $\mathrm{Pt}$ as the counter electrode, and SCE as the reference electrode. The working electrode was first maintained in the test environment for $30 \mathrm{~min}$ before the impedance run. All experiments were conducted at room temperature. All raw data were collected at least three times to ensure reproducibility and statistical significance.

\section{Results and discussion}

\subsection{Spectroscopic studies of VMS particles}

In this study, the as-prepared VMS particles were synthesized from the process of acid-catalyzed solgel reaction of TEOS in the presence of MSMA molecules and subsequently characterized by FTIR, ${ }^{13} \mathrm{C}$ NMR and ${ }^{29} \mathrm{Si}$-NMR spectroscopy. Figure 2a shows the representative FTIR spectroscopy of as-prepared RS and VMS particles. For example, the characteristic peaks located at 1711, 1654 and $1433 \mathrm{~cm}^{-1}$ were assigned to the stretching of $\mathrm{C}=\mathrm{O}, \mathrm{C}=\mathrm{C}$ and $-\mathrm{CH}_{3}$, respectively [29]. The presence of organic groups in the materials after hydrolysis and condensation was confirmed using solid-state NMR spec-
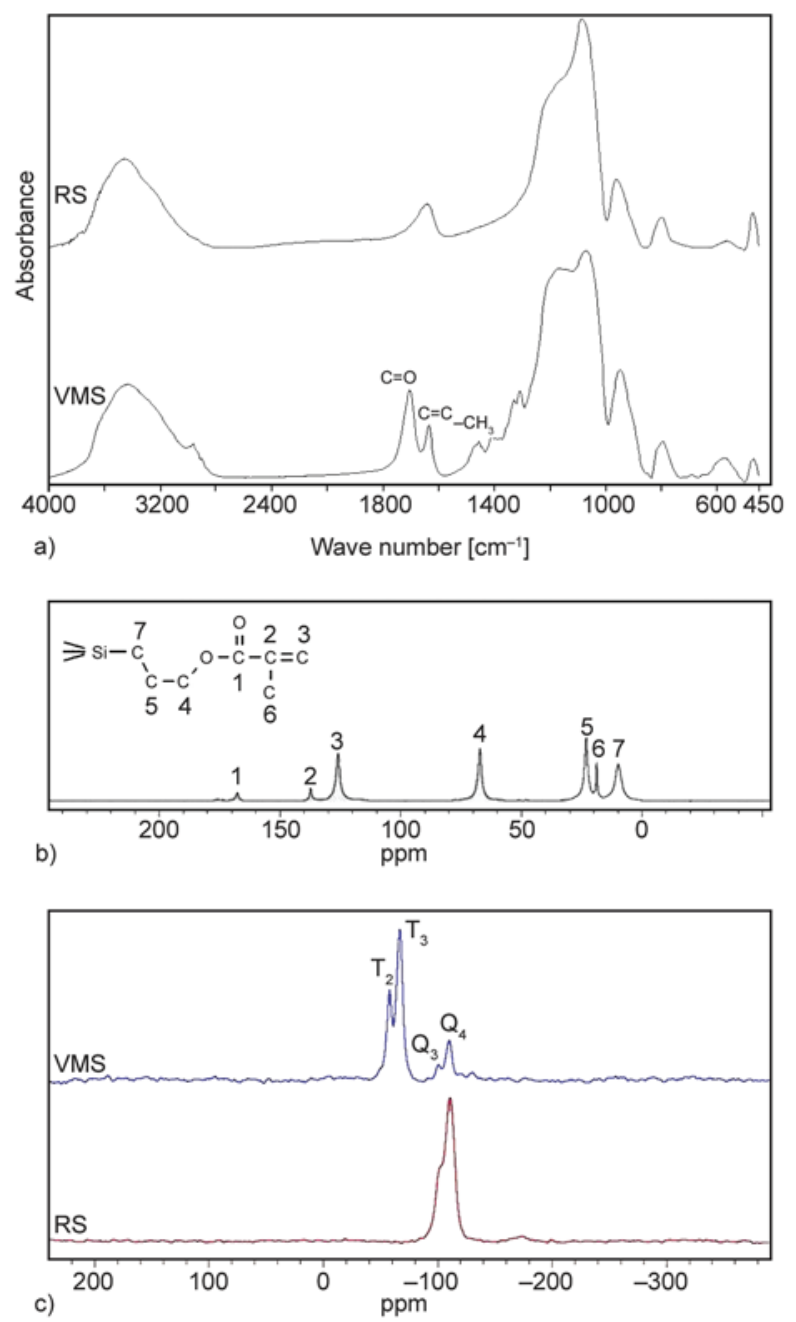

Figure 2. (a) FTIR absorption spectra of RS and VMS particles, (b) ${ }^{13} \mathrm{C}$ CP-MAS NMR spectra of VMS particles, (c) ${ }^{29} \mathrm{Si}$ MAS NMR spectra of RS and VMS particles 
troscopy. The solid-state ${ }^{13} \mathrm{C}$ CP MAS NMR spectra displayed seven resonances for VMS sample, corresponding to vinyl carbons at 127.1 and $137.1 \mathrm{ppm}$ vs. VMS [29], as shown in Figure 2b. Moreover, solid-state ${ }^{29} \mathrm{Si}$ MAS NMR provides information about the silicon environment. The ${ }^{29} \mathrm{Si}$ MAS NMR spectra of RS and VMS samples were presented in Figure 2c. RS particles exhibited two resonances at -100.8 and $-110.4 \mathrm{ppm}$, corresponding to $\mathrm{HOSi}(\mathrm{OSi})_{3}\left(\mathrm{Q}^{3}\right)$ and $\mathrm{Si}(\mathrm{OSi})_{4}\left(\mathrm{Q}^{4}\right)$ silicate species, respectively. Upon modifying the surface with vinyl group using MSMA, the ${ }^{29} \mathrm{Si}$ MAS NMR spectrum show two additional resonances at -56.76 and $-65.96 \mathrm{ppm}$ that were assigned to $\mathrm{R}-\mathrm{Si}(\mathrm{OH})_{2}(\mathrm{OSi})$ $\left(\mathrm{T}^{1}\right)$ and $\mathrm{R}-\mathrm{Si}(\mathrm{OH})(\mathrm{OSi})_{2}\left(\mathrm{~T}^{2}\right)$ centers [29], respectively.

\subsection{Microscopic observations}

A photograph of natural fresh Xanthosoma sagittifolium leaves is shown in Figure 3a. Figure $3 \mathrm{~b}$ is a high-magnification SEM image of the fresh Xanthosoma sagittifolium leaf. The average WCA on the fresh Xanthosoma sagittifolium leaves is $c a$.

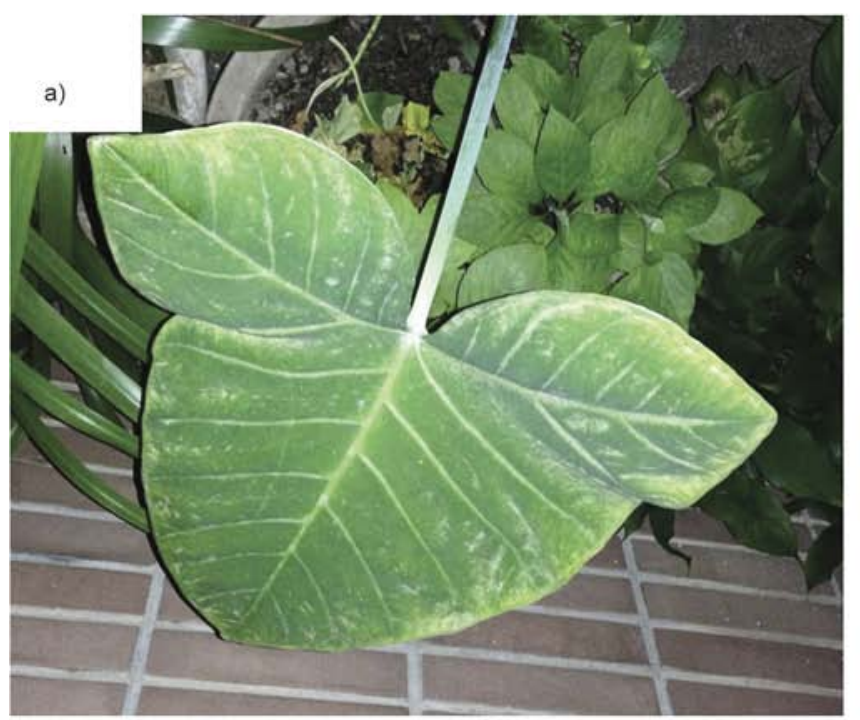

b)
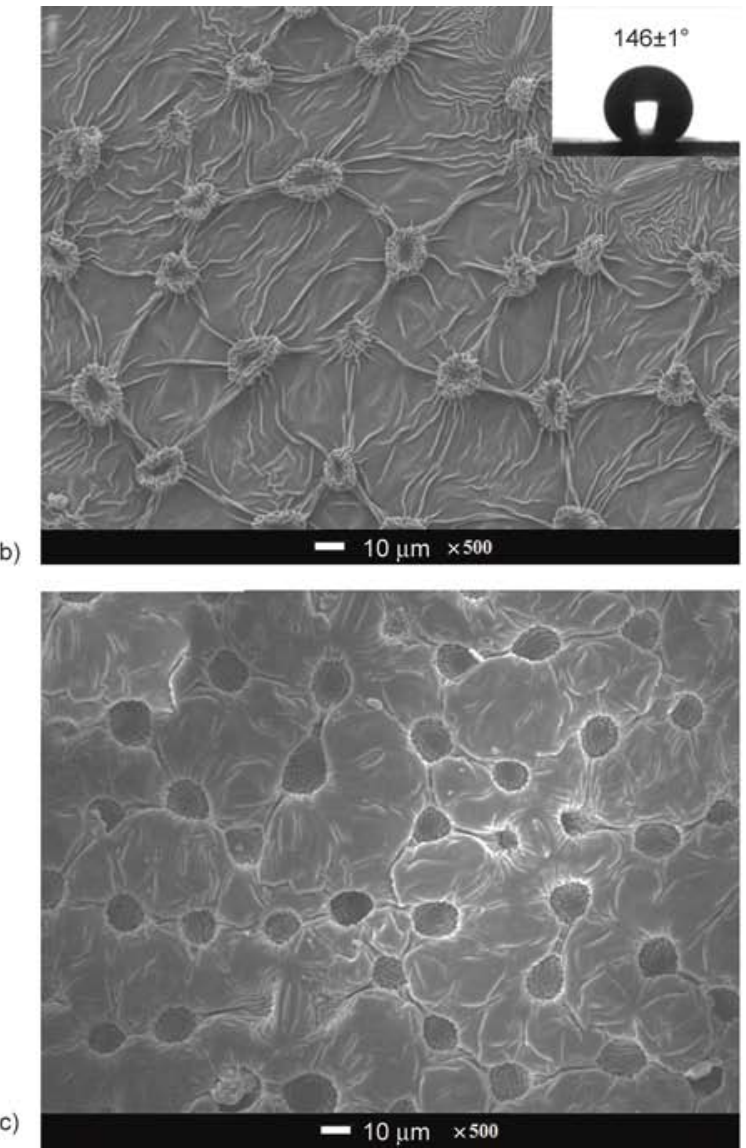

Figure 3. (a) Photograph of Xanthosoma sagittifolium leaves. (b) SEM image of a fresh natural leaf. Illustration shows the water contact angle of a Xanthosoma sagittifolium leaf. (c) PDMS negative template. 

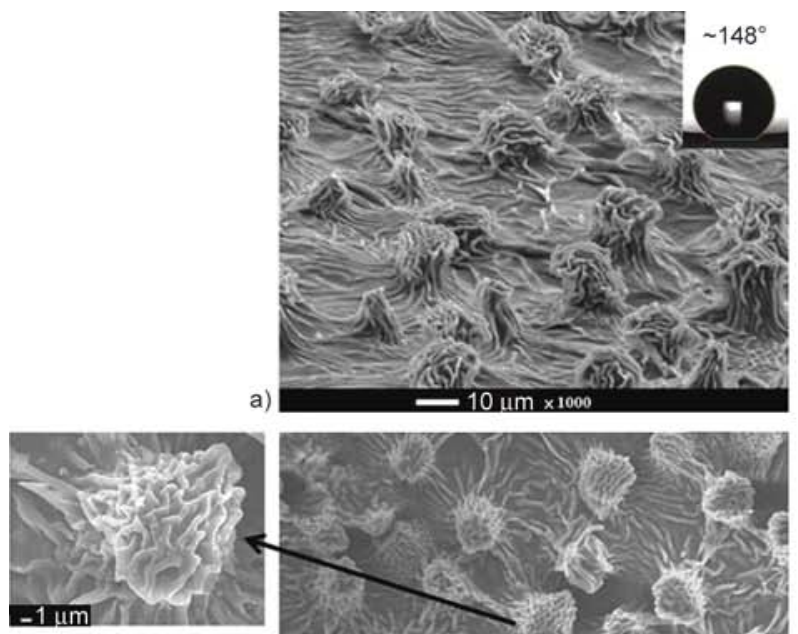

b)
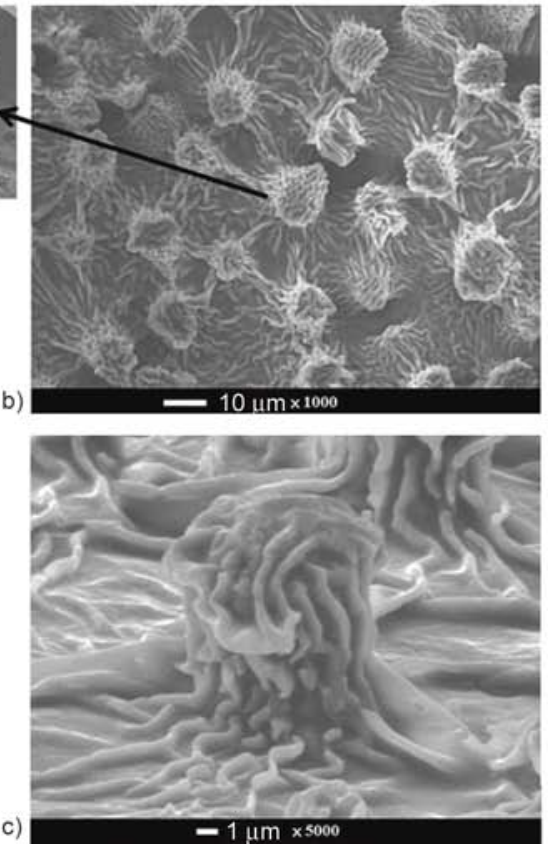
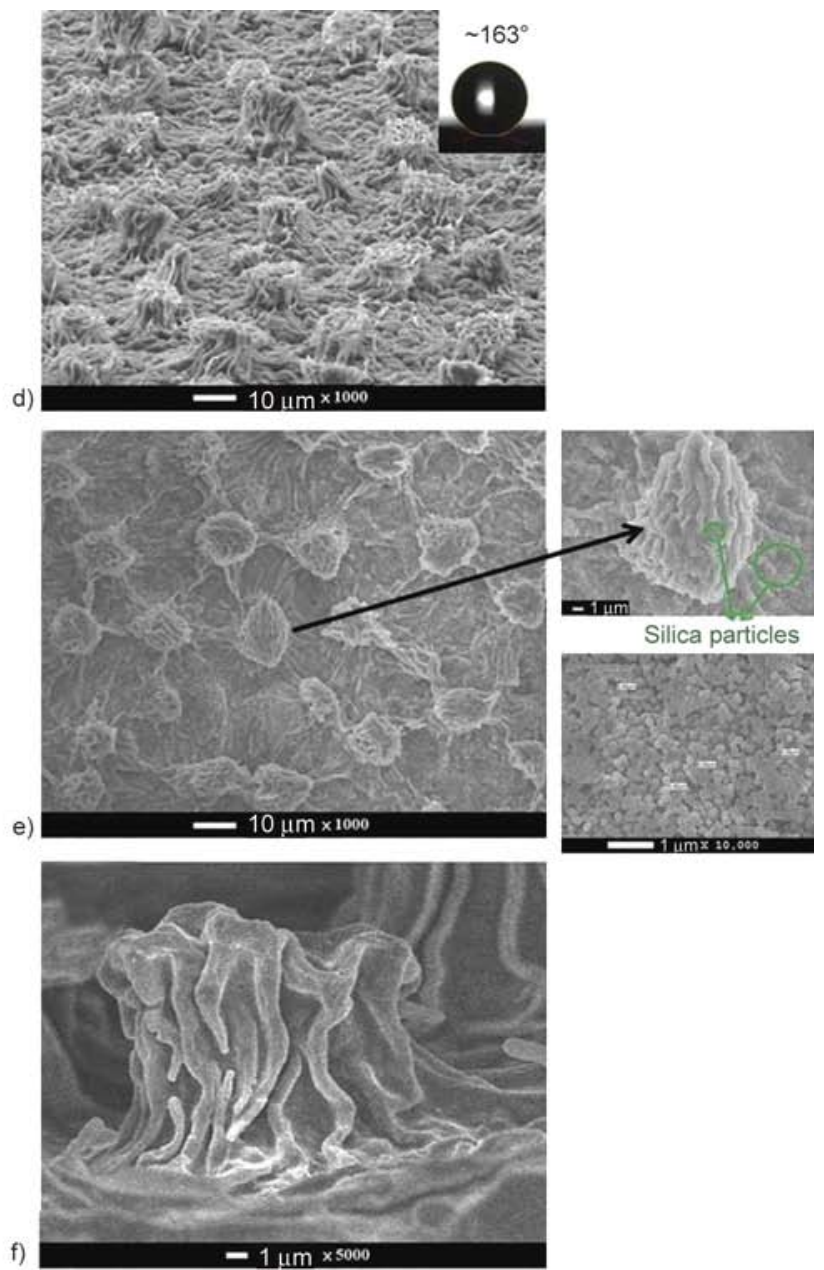

Figure 4. SEM images for (a, d) the Xanthosoma sagittifolium leaf-like hydrophobic surface of PMMA and the superhydrophobic surface of the composite. The inset shows the contact angle of the surface. (b, e) Top views of the surface of PMMA and the composite. The inset of (e) shows the silica particles. (c, f) Section views of the surfaces of PMMA and the composite.

on the papillary and surface microstructures of SPSC (Figure $4 \mathrm{~d}-4 \mathrm{f}$ ). The average size of these nanoparticles is about $340 \pm 40 \mathrm{~nm}$.

The chemical compositions of the surfaces of the HP and SPSC coatings were analyzed by using EDX spectroscopy (Figure 5). The spectrum of HP showed peaks for carbon and oxygen, but no silicon was detected. However, the EDX spectrum of SPSC yielded carbon, oxygen, and silicon peaks. For SPSC, the weight percentages of silicon were 34.20 and $41.15 \%$ for the papillary and surface microstructures, respectively. The presence of the silicon peak indicates that the silica nanoparticles are actually on the papillary and surface microstructures.

In order to better understand the surface topography and the extent of surface roughness on the surfaces of the HP and SPSC coatings, AFM studies were performed in which height images were obtained and average roughness levels of the surfaces were determined. Figure 6 show three-dimensional AFM images of HP and SPSC coatings on CRS substrates. It can be seen that papillary nanostructures, which are replicas of the Xanthosoma sagittifolium leaf, were formed on the surfaces. The surface morphology shown by the AFM images is consistent with the SEM observations. Using these AFM images, the root-mean-square (RMS) roughness levels of the HP and SPSC coatings were measured. The HP coating had an RMS roughness of $1.482 \mu \mathrm{m}$; the SPSC coating displayed a rougher surface consisting of large silica domains with an RMS roughness of $1.645 \mu \mathrm{m}$.

Because providing a surface with nanostructures is essential for fabricating a superhydrophobic surface, we created a superhydrophobic surface by using a nanocasting technique along with silica nanoparticles on the small papillary hills of the bioinspired structure. 

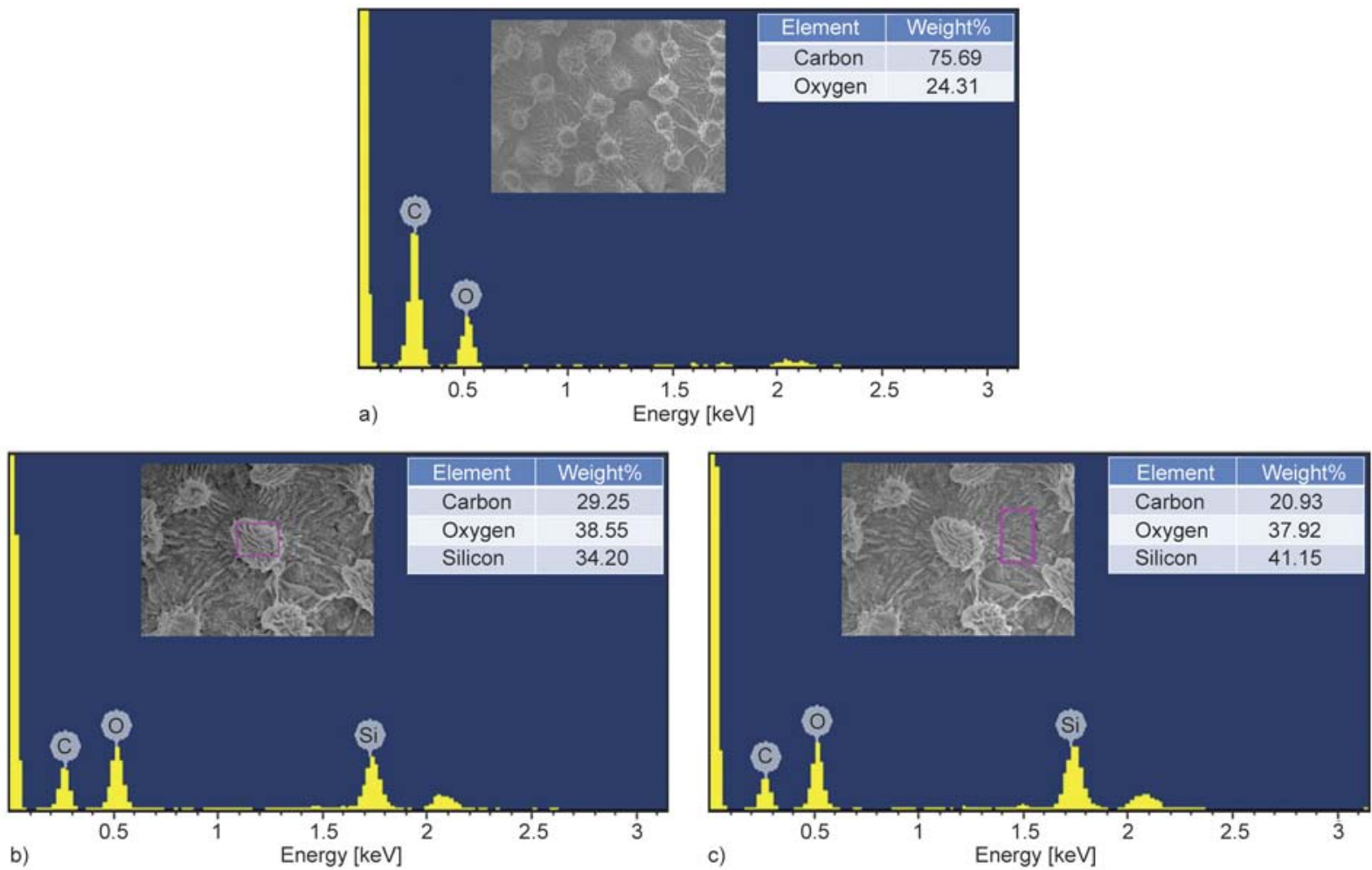

Figure 5. EDX spectra of (a) HP, (b) papillary microstructures of SPSC and (c) the surface microstructure of SPSC
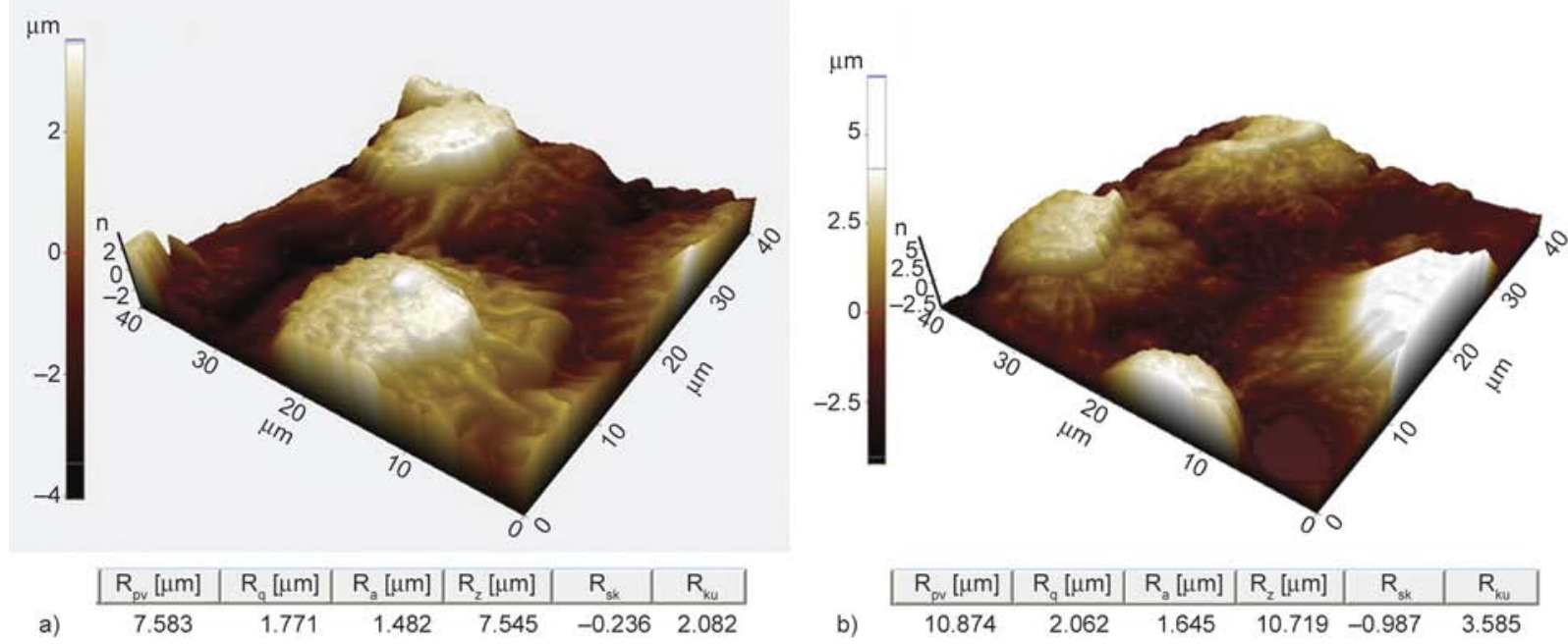

Figure 6. 3D topographical images (a) HP and (b) SPSC surfaces

\subsection{Contact angle (wettability) measurements}

The coating material replicated from the fresh Xanthosoma sagittifolium leaves showed superhydrophobic characteristics and a large WCA. The WCAs of PMMA, HP, PSC, and SPSC are shown in Table 1. The results show that the WCA became as high as $163 \pm 1^{\circ}$ with a hysteresis of $4^{\circ}$ for SPSC. As a significant amount of air was trapped between the papillary hills of the SPSC surface, a water drop on such a coating could only make contact with the tops of the papillary hills. Thus, the water placed on the surface of the SPSC coating was likely resting on a thin air cushion. In addition, the silica nanoparticles increased the roughness of the SPSC coating, which could lead to the formation of more air pockets, trapping more air, and minimizing the contact area; thus, the surface hydrophobicity was further enhanced.

Figure 7 shows the change in the water contact angle with various times for SPSC. The durability of the water repellent on the SPSC coating is a very important parameter. The SPSC was stored at room temperature in the ambient atmosphere for one month, and water contact angles were measured hereafter. Almost no decrease in the water contact 
Table 1. Contact angle and electrochemical corrosion measurements of bare CRS, PMMA, PSC, HP and SPSC coated electrodes

\begin{tabular}{|c|c|c|c|c|c|c|c|c|}
\hline \multirow[b]{2}{*}{$\begin{array}{l}\text { Sample } \\
\text { code }\end{array}$} & \multicolumn{4}{|c|}{ Electrochemical corrosion measurements $^{a}$} & \multirow[b]{2}{*}{$\mathbf{P}_{\mathrm{EF}} \%$} & \multirow[b]{2}{*}{$\begin{array}{c}\text { Thickness } \\
{[\mu \mathrm{m}]}\end{array}$} & \multirow[b]{2}{*}{$\begin{array}{c}\text { Contact angle } \\
{\left[{ }^{\circ} / \mathrm{H}_{2} \mathrm{O}\right]^{\mathrm{b}}}\end{array}$} & \multirow[b]{2}{*}{$\begin{array}{c}\text { Hysteresis angle } \\
{\left[{ }^{\circ} / \mathrm{H}_{2} \mathrm{O}\right] 8}\end{array}$} \\
\hline & $\begin{array}{c}E_{\text {corr }} \\
{[\mathrm{mV} \text { vs SCE] }}\end{array}$ & $\begin{array}{c}\mathbf{R}_{\mathbf{p}} \\
{\left[\mathrm{k} \boldsymbol{\Omega} \cdot \mathrm{cm}^{2}\right]}\end{array}$ & $\begin{array}{c}\mathbf{I}_{\text {corr }} \\
{\left[\boldsymbol{\mu} \mathbf{A} / \mathbf{c m}^{2}\right]}\end{array}$ & $\begin{array}{c}\mathbf{R}_{\text {corr }} \\
{[\mathrm{MPY}]}\end{array}$ & & & & \\
\hline CRS & -825 & 1.15 & 17.45 & 16.24 & - & - & - & - \\
\hline PMMA & -685 & 14.67 & 2.21 & 2.06 & 92.16 & $16 \pm 2$ & $81 \pm 1$ & 1 \\
\hline PSC & -587 & 23.45 & 1.79 & 1.67 & 95.10 & $18 \pm 2$ & $103 \pm 1$ & 1 \\
\hline HP & -501 & 58.27 & 0.75 & 0.70 & 98.03 & $19 \pm 2$ & $148 \pm 1$ & 2 \\
\hline SPSC & -320 & 296.91 & 0.03 & 0.03 & 99.61 & $19 \pm 2$ & $163 \pm 1$ & 4 \\
\hline
\end{tabular}

a) Saturated calomel electrode (SCE) was employed as a reference electrode.

b) The contact angle was determined from the average of five measurements at various positions on the samples' surface.

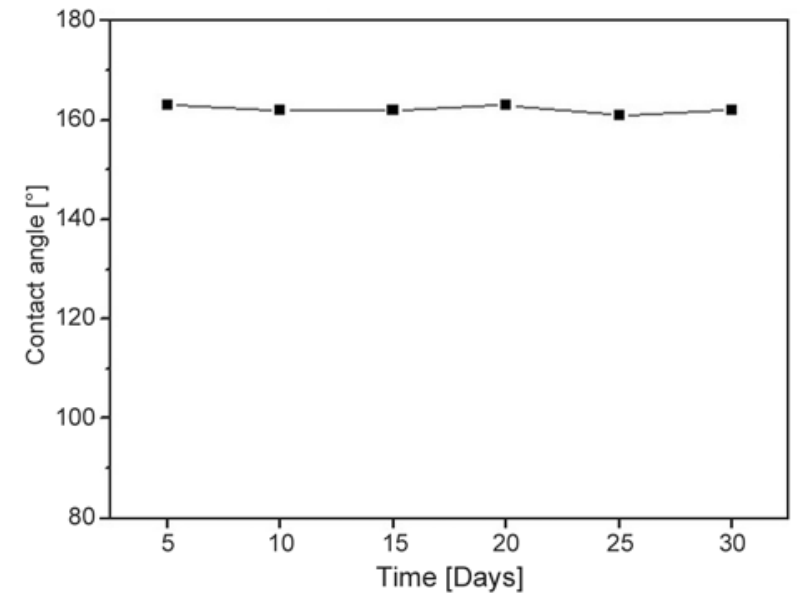

Figure 7. Change in water contact angle with various times for SPSCm

angle was observed, indicating that the superhydrophobic property of the as-prepared SPSC coating is stable enough.

The ability of a coating to protect metal substrates against corrosion depends on three aspects: (1) sorption of water onto the coating, (2) transport of water throughout the coating, and (3) accessibility of water to the coating/substrate interface. Therefore, it is reasonable to accept that the low-wettability SPSC effectively prevented the water from adsorbing onto the substrate surface and therefore exhibited excellent corrosion resistance in wet environments.

\subsection{Potentiodynamic and electrochemical impedance measurements}

On the basis of a series of electrochemical measurements (i.e., corrosion potential, polarization resistance, and corrosion current measured in a corrosive medium (3.5 wt $\%$ aqueous $\mathrm{NaCl}$ electrolyte)), we concluded that the SPSC coating was more effective at protecting the CRS electrode against corrosion than the common HP, PSC, and PMMA coatings. Information about corrosion current can be obtained by extrapolating Tafel plots from both the cathodic and anodic polarization curves for the respective corrosion processes [30]. Extrapolating the cathodic and anodic polarization curves to their point of intersection provides both the corrosion potential and the corrosion current. Corrosion protection studies were performed on samples with $17 \pm 3 \mu$ m-thick coatings and which were immersed in a corrosive medium for $30 \mathrm{~min}$. Tafel plots for the four samples immersed in the corrosive medium are shown in Figure 8; the corresponding data are listed in Table 1. Generally, higher $E_{\text {corr }}$ and polarization resistance, $R_{\mathrm{p}}$, values and lower $I_{\text {corr }}$ and $R_{\text {corr }}$ values indicate better corrosion protection.

The $R_{\mathrm{p}}$ values were evaluated from the Tafel plots according to the Stearn-Geary equation (Equation (2)) [31]:

$$
R_{\mathrm{p}}=\frac{b_{\mathrm{a}} b_{\mathrm{c}}}{2.303\left(b_{\mathrm{a}}+b_{\mathrm{c}}\right)} I_{\text {corr }}
$$

where, $I_{\text {corr }}$ is determined by an intersection of the linear portions of the anodic and cathodic curves

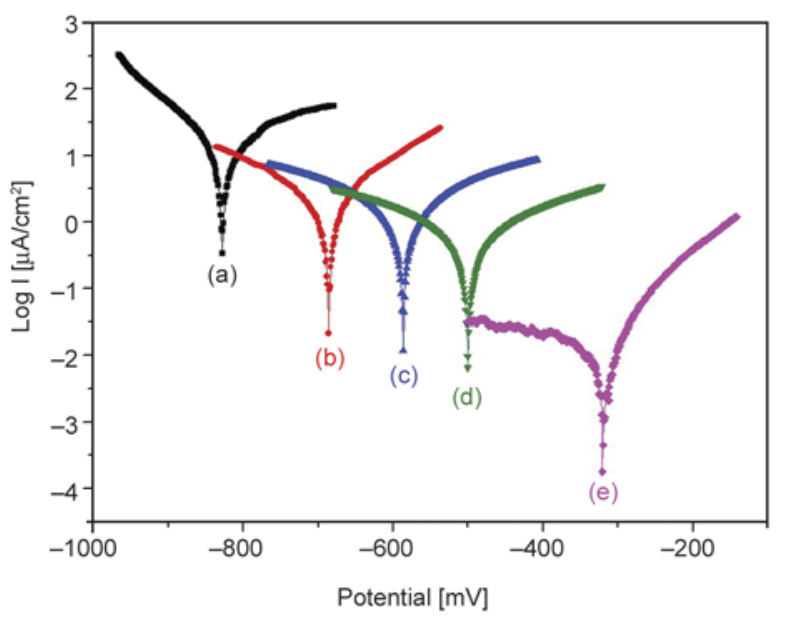

Figure 8. Tafel plots for (a) bare, (b) PMMA-coated, (c) PSCcoated, (d) HP-coated and (e) SPSC-coated CRS electrodes measured at $25 \pm 0.5^{\circ} \mathrm{C}$ 
and $b_{\mathrm{a}}$ and $b_{\mathrm{c}}$ are the anodic and cathodic Tafel slopes (i.e., $\Delta E / \Delta \log I)$, respectively.

The Tafel plots for the sample-coated CRS electrodes indicate corrosion potentials of $E_{\text {corr }}=-685$, -587, and $-501 \mathrm{mV}$ for the PMMA, PSC and HP coatings, respectively, which were more positive than that for the bare CRS electrode, for which $E_{\text {corr }}=-825 \mathrm{mV}$. Moreover, the corrosion currents $\left(I_{\text {corr }}\right)$ of the PMMA, PSC, and HP-coated CRS electrodes were $c a .2 .21,1.79$, and $0.75 \mu \mathrm{A} / \mathrm{cm}^{2}$, which were significantly lower than that of the bare CRS electrode (i.e., $17.45 \mu \mathrm{A} / \mathrm{cm}^{2}$ ).

The corresponding $I_{\text {corr }}$ and $R_{\text {corr }}$ decreased considerably when we used the PSC-coated bare CRS electrode with Xanthosoma sagittifolium-leaf-like structures (SPSC) to obtain superhydrophobic properties. Moreover, the $E_{\text {corr }}$ and $R_{\mathrm{p}}$ of the SPSC-coated CRS electrode was more positive and larger than that of the HP-coated CRS electrode, as $E_{\text {corr }}$ and $R_{\mathrm{p}}$ increased from -501 to $-320 \mathrm{mV}$ (vs. SCE) and 58.27 to $296.91 \mathrm{k} \Omega \cdot \mathrm{cm}^{2}$, respectively, for the SPSCcoated CRS electrode.

The protection efficiency $\left(P_{\mathrm{EF}} \%\right)$ values were estimated using the Equation (3) [32]:

$$
P_{\mathrm{EF}} \%=100 \frac{R_{\mathrm{p}}^{-1}(\text { uncoated })-R_{\mathrm{p}}^{-1}(\text { coated })}{R_{\mathrm{p}}^{-1}(\text { uncoated })}
$$

The SPSC coatings exhibited a $P_{\mathrm{EF}}$ of $99.61 \%$, suggesting that SPSC is more effective in preventing electrochemical corrosion than PMMA, PSC, and HP, which had $P_{\mathrm{EF}}$ values of $92.16,95.10$, and $98.03 \%$, respectively.

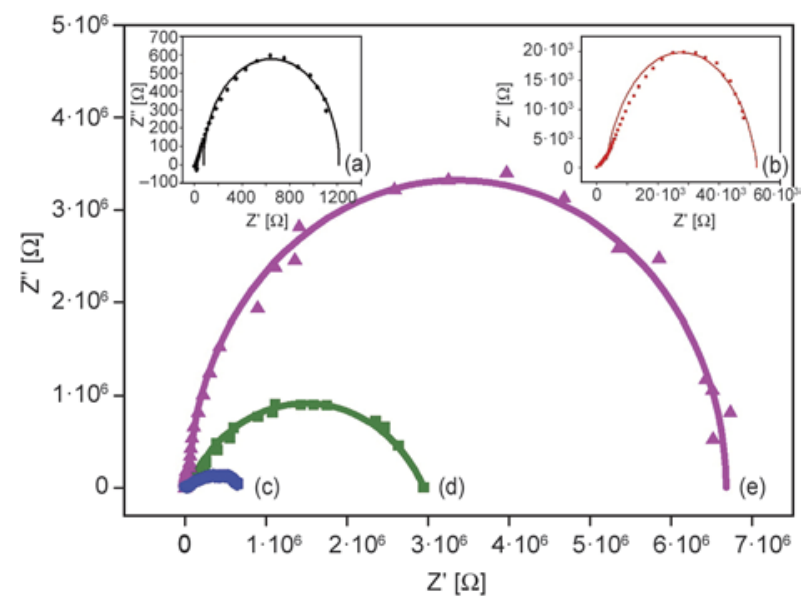

Figure 9. Nyquist plots for (a) bare, (b) PMMA-coated, (c) PSC-coated, (d) HP-coated, and (e) SPSCcoated CRS electrodes
Figure 9 shows the Nyquist plots of the four measured samples. The first sample (a) is uncoated CRS. A series of samples denoted as (b), (c), (d), and (e) represent the CRS-coated by PMMA, PSC, HP, and SPSC, respectively. The charge transfer resistances of all samples, as determined by subtracting the intersection of the high-frequency end from the low-frequency end of the semicircle arc with the real axis, were $0.001,0.048,0.645,2.95$, and $6.52 \mathrm{M} \Omega \cdot \mathrm{cm}^{2}$. EIS Bode plots (impedance vs. frequency) of all samples are shown in Figure 10. $Z_{\text {real }}$ is a measure of corrosion resistance [33]. Low $Z_{\text {real }}$ value could be brought about by very high capacitance and/or very low resistance of the coating [34]. Large value of the capacitance has been related to the high extent at which water has penetrated the coating [35]. In the case of Bode plots, the value of $Z_{\text {rea }} 1$ at the lowest frequency also represents the corrosion resistance. The Bode magnitude plots for uncoated CRS and CRS-coated by PMMA, PSC,

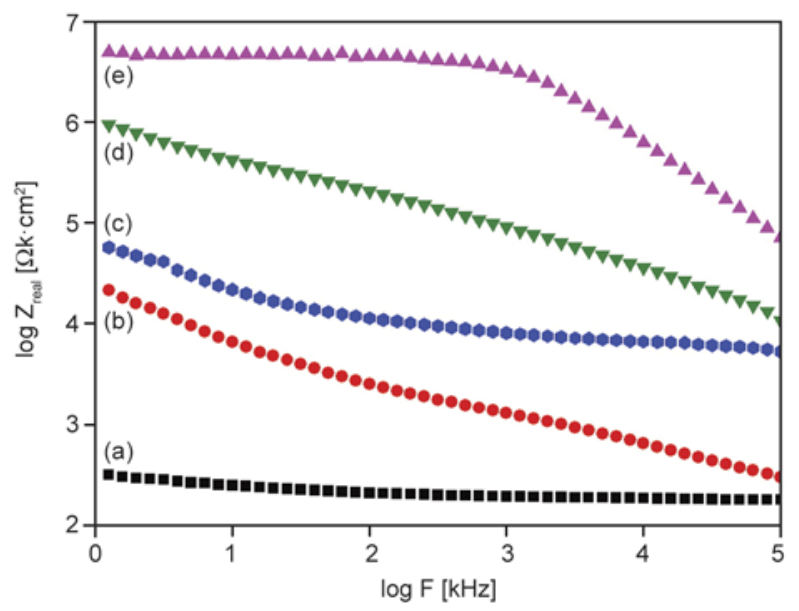

Figure 10. Bode plots for (a) bare, (b) PMMA-coated, (c) PSC-coated, (d) HP-coated and (e) SPSCcoated CRS electrodes

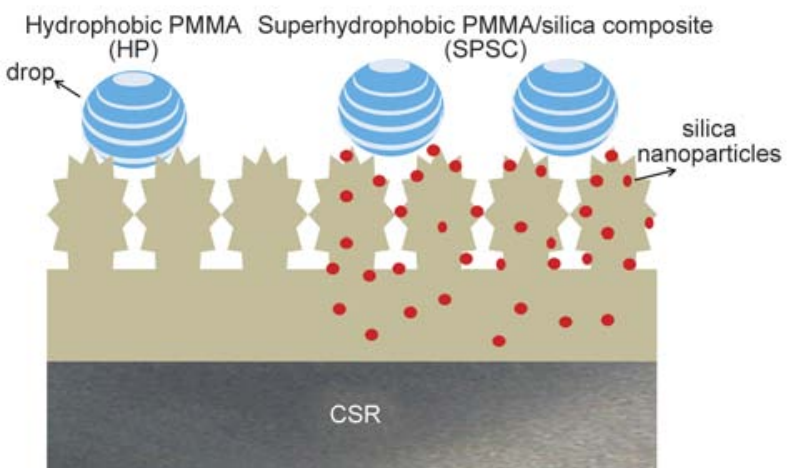

Figure 11. Schematic representation of hydrophobic and superhydrophobic surfaces of HP and SPSC coatings 
HP, and SPSC shows $Z_{\text {real values of } 2.5,4.3,4.8,6.0}$ and $6.7 \mathrm{k} \Omega \cdot \mathrm{cm}^{2}$, respectively, at low frequency end. The electrochemical results show that the SPSC coating provided better protection against corrosion of the CRS electrode than the other coatings did; this is mainly attributed to the superhydrophobicity of the SPSC coating compared to HP, PSC, and PMMA coatings, which may have resulted from the super water-repellent property, as shown in Figure 11 . This is evidenced by the contact angle (wettability) measurements of the as-prepared coatings.

\section{Conclusions}

Advanced anticorrosion coatings of PSC with bioinspired Xanthosoma sagittifolium leaf-like superhydrophobic surfaces were successfully prepared by using a nanocasting method along with a UVcuring technique. Surface morphologies of as-prepared SPSC coatings were found to contain a large number of micro-scaled mastoids, each decorated with many nano-scaled wrinkles. The WCA of the SPSC coating whose surface was imprinted with the bioinspired pattern of the surface of a natural leaf was about $163^{\circ}$, which was significantly larger than that of the HP coating (i.e., $\mathrm{WCA}=148^{\circ}$ ). This is because the silica nanoparticles on the small papillary hills of the bioinspired structure enhanced the surface hydrophobicity to a superhydrophobic degree. The superhydrophobicity of SPSC materials affords them excellent anticorrosive properties.

\section{Acknowledgements}

The authors acknowledge financial support from the Ministry of Science and Technology, Taiwan, R.O.C. (NSC 1012113-M-033-005-MY3), and the Center for Nanotechnology and Biomedical Technology at CYCU.

\section{References}

[1] Edinger C., Grimaudo V., Broekmann P., Waldvogel S. R.: Stabilizing lead cathodes with diammonium salt additives in the deoxygenation of aromatic amides. ChemElectroChem, 1, 1018-1022 (2014). DOI: $10.1002 /$ celc. 201402050

[2] Chirkunov A. A., Gorbachev A. S., Kuznetsov Y. I., Shikhaliev K. S.: Inhibition of anodic dissolution of lowcarbon steel with alkyl phosphonates in borate buffer solution. Protection of Metals and Physical Chemistry of Surfaces, 48, 769-772 (2012).

DOI: $10.1134 / \mathrm{S} 2070205112070040$
[3] Correa E., Zuleta A. A., Guerra L., Gómez M. A., Castaño J. G., Echeverría F., Liu H., Skeldon P., Thompson G. E.: Tribological behavior of electroless Ni-B coatings on magnesium and AZ91D alloy. Wear, 305, 115123 (2013).

DOI: 10.1016/j.wear.2013.06.004

[4] Lai S. C. S.: Mimicking nature: Physical basis and artificial synthesis of the Lotus-effect. University of Leiden, Leiden (2003).

[5] Extrand C. W.: Model for contact angles and hysteresis on rough and ultraphobic surfaces. Langmuir, 18, 79917999 (2002).

DOI: $10.1021 / 1 \mathrm{a} 025769 \mathrm{z}$

[6] Chen L., Yang G., Wang S.: Air-grid surface patterning provided by superhydrophobic surfaces. Small, 8, 962965 (2012).

DOI: $10.1002 / \mathrm{smll} .201102345$

[7] Oliveira N. M., Reis R. L., Mano J. F.: Superhydrophobic surfaces engineered using diatomaceous earth. ACS Applied Materials and Interfaces, 5, 4202-4208 (2013). DOI: 10.1021/am4003759

[8] Sun M., Luo C., Xu L., Ji H., Oujang Q., Yu D., Chen Y.: Artificial lotus leaf by nanocasting. Langmuir, 21, 8978-8981 (2005). DOI: $10.1021 / 1 \mathrm{a} 050316 \mathrm{q}$

[9] Zang D., Li F., Geng X., Lin K., Clegg P. S.: Tuning the wettability of an aluminum surface via a chemically deposited fractal dendrite structure. The European Physical Journal E, 36, 59/1-59/8 (2013).

DOI: 10.1140/epje/i2013-13059-2

[10] Mahadik S. A., Fernando P. D., Hegade N. D., Wagh P. B., Gupta S. C.: Durability and restoring of superhydrophobic properties in silica-based coatings. Journal of Colloid and Interface Science, 405, 262-268 (2013). DOI: $10.1016 /$ j.jcis.2013.04.042

[11] Wang J., Song X., Rui L., Shen J., Yang G., Huang H.: Fluorocarbon thin film with superhydrophobic property prepared by pyrolysis of hexafluoropropylene oxide. Applied Surface Science, 258, 9782-9785 (2012). DOI: $10.1016 /$ j.apsusc.2012.06.029

[12] Ou J., Hu W., Xue M., Wang F., Li W.: Superhydrophobic surfaces on light alloy substrates fabricated by a versatile process and their corrosion protection. ACS Applied Materials and Interfaces, 5, 3101-3107 (2013). DOI: 10.1021/am4000134

[13] Gu H. Y., Qi Z. Y., Wu W., Zeng Y., Song L. X.: Superhydrophobic polyimide films with high thermal endurance via UV photo-oxidation. Express Polymer Letters, 8, 588-595 (2014).

DOI: $10.3144 /$ expresspolymlett.2014.62

[14] Wu Z., Wang H., Xue M., Tian X., Ye X., Zhou H., Cui Z.: Facile preparation of superhydrophobic surfaces with enhanced releasing negative air ions by a simple spraying method. Composites Science and Technology, 94, 111-116 (2014).

DOI: $\underline{10.1016 / \text { j.compscitech.2014.01.019 }}$ 
[15] Bayer I. S., Steele A., Loth E.: Superhydrophobic and electroconductive carbon nanotube-fluorinated acrylic copolymer nanocomposites from emulsions. Chemical Engineering Journal, 221, 522-530 (2013). DOI: $10.1016 /$ j.cej.2013.01.023

[16] Wolfs M., Darmanin T., Guittard F.: Superhydrophobic nanofiber arrays and flower-like structures of electrodeposited conducting polymers. Soft Matter, 8, 91109114 (2012).

DOI: $10.1039 / \mathrm{C} 2 \mathrm{SM} 26274 \mathrm{~F}$

[17] Chen Z. M., Pan S. J., Yin H. J., Zhang L. L., Ou E. C., Xiong Y. Q., Xu W. J.: Facile synthesis of superhydrophobic $\mathrm{TiO}_{2}$ /polystyrene core-shell microspheres. Express Polymer Letters, 5, 38-46 (2011). DOI: $10.3144 /$ expresspolymlett.2011.5

[18] Ding X., Zhou S., Gu G., Wu L.: A facile and largearea fabrication method of superhydrophobic self-cleaning fluorinated polysiloxane/ $/ \mathrm{TiO}_{2}$ nanocomposite coatings with long-term durability. Journal of Materials Chemistry, 21, 6161-6164 (2011). DOI: $10.1039 / \mathrm{C} 0 J M 04546 \mathrm{~B}$

[19] Schutzius T. M., Tiwari M. K., Bayer I. S., Megaridis C. M.: High strain sustaining, nitrile rubber based, large-area, superhydrophobic, nanostructured composite coatings. Composites Part A: Applied Science and Manufacturing, 42, 979-985 (2011). DOI: $10.1016 /$ j.compositesa.2011.03.026

[20] Manoudis P. N., Karapanagiotis I., Tsakalof A., Zuburtikudis I., Panayiotou C.: Superhydrophobic composite films produced on various substrates. Langmuir, 24, 11225-11232 (2008) DOI: $10.1021 / 1 \mathrm{a} 801817 \mathrm{e}$

[21] Yilgor I., Bilgin S., Isik M., Yilgor E.: Facile preparation of superhydrophobic polymer surfaces. Polymer, 53, 1180-1188 (2012). DOI: 10.1016/j.polymer.2012.01.053

[22] Grignard B., Vaillant A., de Coninck J., Piens M., Jonas A. M., Detrembleur C., Jerome C.: Electrospinning of a functional perfluorinated block copolymer as a powerful route for imparting superhydrophobicity and corrosion resistance to aluminum substrates. Langmuir, 27, 335-342 (2011). DOI: $10.1021 / 1 \mathrm{a} 102808 \mathrm{w}$

[23] de Leon A. C. C., Pernites R. B., Advincula R. C.: Superhydrophobic colloidally textured polythiophene film as superior anticorrosion coating. ACS Applied Materials and Interfaces, 4, 3169-3176 (2012).

DOI: $10.1021 / \mathrm{am} 300513 \mathrm{e}$

[24] Singh B. P., Jena B. K., Bhattacharjee S., Besra L.: Development of oxidation and corrosion resistance hydrophobic graphene oxide-polymer composite coating on copper. Surface and Coatings Technology, 232, 475-481 (2013).

DOI: $10.1016 /$ j.surfcoat.2013.06.004
[25] Peng C-W., Chang K-C., Weng C-J., Lai M-C., Hsu CH., Hsu S-C., Li S-Y., Wei Y., Yeh J-M.: UV-curable nanocasting technique to prepare bio-mimetic superhydrophobic non-fluorinated polymeric surfaces for advanced anticorrosive coatings. Polymer Chemistry, 4, 926-932 (2013).

DOI: $10.1039 / \mathrm{C} 2 \mathrm{PY} 20613 \mathrm{G}$

[26] Chang K-C., Ji W-F., Lai M-C., Hsiao Y-R., Hsu C-H., Chuang T-L., Wei Y., Yeh J-M, Liu W-R.: Synergistic effects of hydrophobicity and gas barrier properties on the anticorrosion property of PMMA nanocomposite coatings embedded with graphene nanosheets. Polymer Chemistry, 5, 1049-1056 (2014).

DOI: $10.1039 / \mathrm{C} 3 \mathrm{PY} 01178 \mathrm{~J}$

[27] Yeh J-M., Chang K-C., Peng C-W., Chiou S-C., Hwang S-S., Yang J-C., Lin H-R.: Effect of vinyl-modified silica and raw silica particles on the properties of as-prepared polymer-silica nanocomposite foams. Journal of Nanoscience and Nanotechnology, 8, 6297-6305 (2008). DOI: $10.1166 /$ jnn.2008.354

[28] Wei Y., Wang J., Jia X., Yeh J-M., Spellane P.: Polyaniline as corrosion protection coatings on cold rolled steel. Polymer, 36, 4535-4537 (1995). DOI: 10.1016/0032-3861(95)96866-7

[29] Yu Y-Y., Chen C-Y., Chen W-C.: Synthesis and characterization of organic-inorganic hybrid thin films from poly(acrylic) and monodispersed colloidal silica. Polymer, 44, 593-601 (2003). DOI: $10.1016 / \mathrm{S} 0032-3861(02) 00824-8$

[30] Beving D. E., McDonnell A. M. P., Yang W. S., Yan Y. S.: Corrosion resistant high-silica-zeolite MFI coating. One general solution formulation for aluminum alloy AA-2024-T3, AA-5052-H32, AA-6061-T4, and AA7075-T6. Journal of the Electrochemical Society, 153, B325-B329 (2006).

DOI: $10.1149 / 1.2207845$

[31] Stern M., Geary A. L.: Electrochemical polarization. I. A theoretical analysis of the shape of polarization curves. Journal of the Electrochemical Society, 104, 56-63 (1957).

DOI: $10.1149 / 1.2428496$

[32] Bockris J., Reddy K. N.: Modern electrochemistry. Plenum Press, New York (1976).

[33] Zucchi F., Grassi V., Frignani A., Monticelli C., Trabanelli G.: Electrochemical behaviour of a magnesium alloy containing rare earth elements. Journal of Applied Electrochemistry, 36, 195-204 (2006). DOI: $10.1007 / \mathrm{s} 10800-005-9053-3$

[34] Kannan M. B., Gomes D., Dietzel W., Abetz V.: Polyoxadiazole-based coating for corrosion protection of magnesium alloy. Surface and Coatings Technology, 202, 4598-4601 (2008). DOI: 10.1016/j.surfcoat.2008.03.027

[35] Rammelt U., Reinhard G.: Application of electrochemical impedance spectroscopy (EIS) for characterizing the corrosion-protective performance of organic coatings on metals. Progress in Organic Coatings, 21, 205-226 (1992).

DOI: $10.1016 / 0033-0655(92) 87005-\mathrm{U}$ 